\title{
Placenta in pregnancy induced hypertension
}

\section{Pooja Kashinath Bandekar*, Prashant Bhimrao Kale}

Department of Obstetrics and Gynecology, Seth G. S. Medical College, Nowrosjee Wadia Maternity Hospital, Parel, Mumbai, Maharashtra, India

Received: 12 January 2018

Accepted: 16 January 2018

\section{* Correspondence:}

Dr. Pooja Kashinath Bandekar,

E-mail: pujuobgy@gmail.com

Copyright: () the author(s), publisher and licensee Medip Academy. This is an open-access article distributed under the terms of the Creative Commons Attribution Non-Commercial License, which permits unrestricted non-commercial use, distribution, and reproduction in any medium, provided the original work is properly cited.

\begin{abstract}
Background: Placenta is a predictor of outcome of pregnancy. Placental examination holds an important role in improving outcome of pregnancy. It is strategically located at feto-maternal interface and it acts like a record of pregnancy in which the cumulative effects of pregnancy related events and changes reflecting the intrauterine environment can be scrutinized. Objective of present study was to diagnose presence, if at all, of lesions of placenta and their nature in cases of pregnancy induced hypertension specifically in $2^{\text {nd }}$ and $3^{\text {rd }}$ trimester of pregnancy and to classify the lesions based on clinical presentation and to compare the results.

Methods: This study is based on histopathological examination of placenta in cases of PIH over a period of three years, from May 2011 to April 2014. The study was carried out at a tertiary care hospital.

Results: There were $280(19.4 \%)$ cases of PIH amongst a total of 1440 cases. In these 280, $170(60.72 \%)$ cases had severe PIH, 110 (39.28\%) cases had mild PIH. Also, 180 (16.28\%) cases revealed increased morbidity and mortality. Conclusions: Evaluation of placenta is an extremely important predictor, that helps to improve the outcome of pregnancy.
\end{abstract}

Keywords: Placenta, PIH, Predictor

\section{INTRODUCTION}

The entire existence of fetus in utero is solely dependent on only one vital organ "The Placenta". Placenta is essential for both maintenance and promotion of growth and development of fetus. ${ }^{1}$ The most accurate record of the infant's prenatal experience is the placenta. $^{2}$ Pregnancy-induced hypertension $(\mathrm{PIH})$ is the leading cause of maternal, fetal and neonatal mortality.

Pregnancy complications reflect in a significant way, both macroscopically and microscopically, in the placenta. Several studies have shown that there is uteroplacental insufficiency in PIH due to maternal vasospasm. ${ }^{3}$ This leads to vaso constriction of fetal stem arteries and hence the changes seen in the placenta of preeclamptic women. ${ }^{4}$
Maternal vasospasm leads to fetal hypoxia and also may lead to fetal distress and fetal death. ${ }^{5}$ The placenta is the mirror of maternal and fetal status. This study was carried out to diagnose changes, gross and microscopic, in placenta in cases of pregnancy induced hypertension over a period of 3 years from May 2011 to April 2014.

\section{METHODS}

This study consists histopathological examination of placentae in cases of PIH from May 2011 to April 2014. The study was carried out at a tertiary care hospital.

All the placentae in cases of pregnancy induced hypertension, in $2^{\text {nd }}$ and $3^{\text {rd }}$ trimesters of pregnancy were included in the study. Placentae of first trimester of pregnancy were excluded from the study. 
Placenta, membranes and umbilical cord were submitted to the pathology department for examination. After receiving the specimen it was washed in running tap water, weighed and cut into vertical segments of $1-2 \mathrm{~cm}$ thickness from maternal to fetal surface to ensure proper fixation and then it was fixed in adequate volume of $10 \%$ formalin for 1 week. All the placentae were handled in accordance to Universal precautions. Thorough gross examination of the placenta was done with careful review of the umbilical cord, placental membranes, fetal and maternal surfaces. All significant lesions were noted. The diagnosis was further made on microscopy in the light of clinical details and investigations.

\section{RESULTS}

We observed $280(19.4 \%)$ cases of PIH amongst a total of 1440 cases (Figure 1).

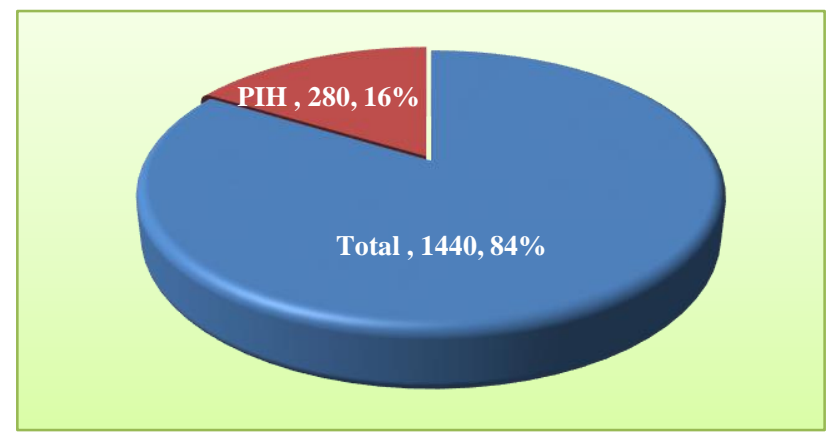

Figure 1: Proportion of PIH.

$170(60.72 \%)$ were having severe PIH, while 110 $(39.28 \%)$ were having mild PIH. Out of total 280 cases of $\mathrm{PIH}, 180(16.28 \%)$ cases showed high morbidity and mortality which included, abruptio placentae 80 , DIC 20 , HELLP syndrome 10 intra uterine losses 52, still births 9, eclampsia 9 cases (Table 1).

Table 1: Complications.

\begin{tabular}{|lll|}
\hline Pathology & Number & Percentage \\
\hline Abruptio placentae & 80 & 44.40 \\
\hline DIC & 20 & 11.11 \\
\hline HELLP & 10 & 5.56 \\
\hline Intra-uterine losses & 52 & 28.89 \\
\hline Still births & 9 & 5 \\
\hline Eclampsia & 9 & 5 \\
\hline Total & 180 & \\
\hline
\end{tabular}

Amongst severe PIH cases, 130 (76.4\%) placentae showed low placental weight, in mild PIH only 20 $(18.2 \%)$ placentae showed the same for the corresponding gestational age. It revealed that low placental weight was significantly associated with PIH (Chi-square $=6.930$ and $\mathrm{P}$ value 0.08$)$. Weight of baby was smaller than expected, for the corresponding gestational age in $140(82.3 \%)$ cases of severe PIH and $40(35 \%)$ cases of mild PIH. It revealed that low birth weight was significantly associated with PIH (Chi-square $=4.312$ and $\mathrm{P}$ value 0.03).

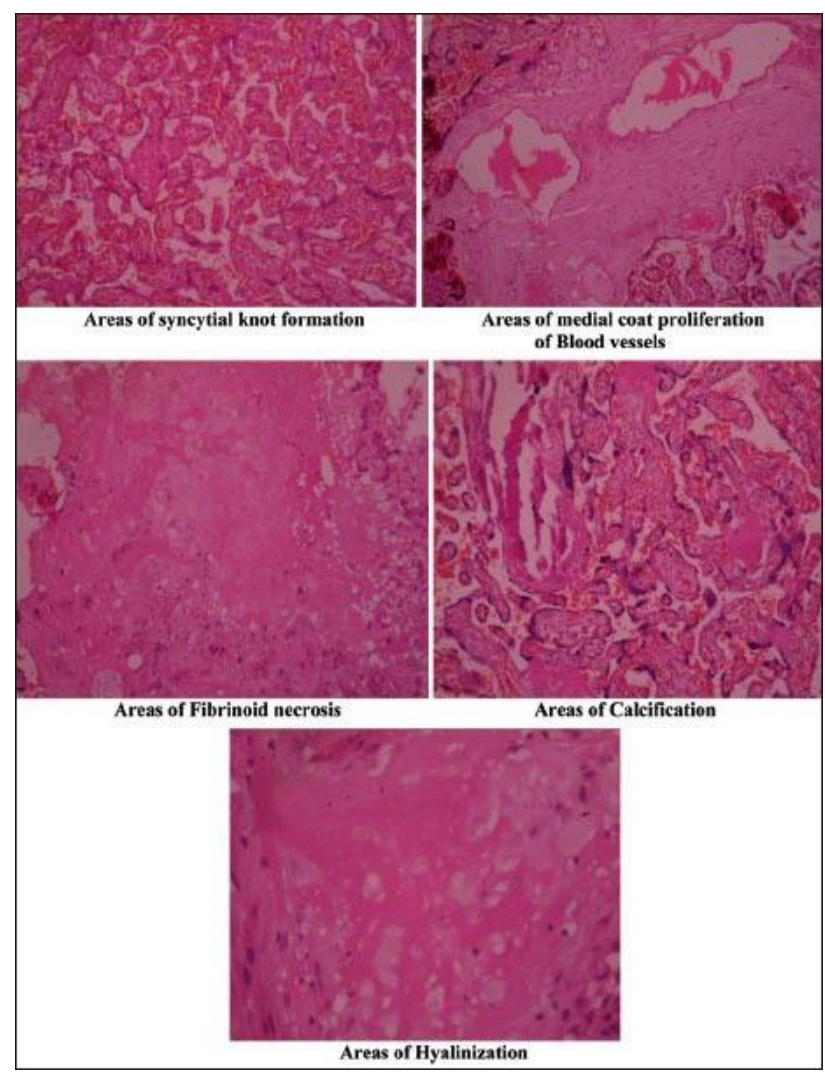

Figure 2: Histopathological changes.

Placentae were smaller in PIH. Commonest pathology seen was large multifocal infarcts, in 120 (42.85\%) cases, followed by retro- placental clot in $80(28.50 \%)$ cases, abruptio placentae $80(22.40 \%)$ cases and calcification in $20(7 \%)$ cases (Figure 2). The base and edge infarcts were most extensive. Infarcts were seen in $100(58 \%)$ cases of severe PIH and $20(18.2 \%)$ cases of mild PIH. Uteroplacental insufficiency (UPI) was the major pathological diagnosis in $78.6 \%$ cases as documented in literature. ${ }^{6}$ Uteroplacental insufficiency (UPI) reflected increased infarcts, syncytial knots, maternal vessel thrombosis and fibrinoid necrosis.

\section{DISCUSSION}

The study included $280(19.4 \%)$ cases of PIH. $60 \%$ of cases revealed severe PIH. Similar observations found in study by Narasimha A et al. ${ }^{7}$ In this study increased morbidity and mortality included abruption placentae 80 , DIC 20, HELLP syndrome 10, intra uterine losses 52, still births 9, eclampsia 9 cases. An almost similar clinical outcome was obtained by Alexander et al who studied 6518 patients with $\mathrm{PIH}^{8}{ }^{8}$

On gross examination, small placentae and large multifocal infarcts in $120(42.85 \%)$ cases is the commonest pathology, followed by retroplacental clot 80 
(28.5\%) cases, abruption $60 \quad(21.42 \%)$ cases and calcification $20(7 \%)$ cases. The basal and edge infarcts of placenta were extensive and more commonly seen in cases of severe PIH. An alteration in the hormonal facto probably leads to altered blood flow and hence a significant increase in syncytial knot formation in placental. According to Robertson, the cause of reduction in blood flow is due to vasculopathies of spiral arteries, which in turn causes reduction in the weight of placenta. It has been recorded that maternal utero-placental blood flow is decreased in preeclampsia because of maternal vasospasm. Reduced maternal utero-placental blood flow indirectly leads to constriction of fetal stem arteries. ${ }^{6(9)}$

It revealed that low placental weight was significantly associated with severe PIH. These findings correlated with other studies. ${ }^{6,10,11}$ Weight of baby was smaller than expected gestational age in 140 cases $(82.3 \%)$ of severe $\mathrm{PIH}$, and 40 cases $(35 \%)$ of mild PIH. It revealed that low birth weight was significantly associated with severe PIH which correlate with findings of other studies. ${ }^{6,10-14}$

\section{CONCLUSION}

PIH contributed to $19.4 \%$ of cases amongst all the placentae received. Placental examination helps reveal increased morbidity and mortality in the form of low placental weight and associated low birth weight of baby. The histopathological changes of PIH and uteroplacental insufficiency revealed various structural changes such as significant number of syncytial knots, areas of fibrinoid necrosis, areas of medial coat proliferation of medium sized blood vessels, areas of calcification, and areas of hyalinization. Thus placental changes occuring in PIH directly affect the growth and nutrition of fetus in utero. A detailed history, clinical examination and investigations of mother and ultrasonography play an essential role in the interpretation of histopathological diagnosis of placental lesions.

Funding: No funding sources Conflict of interest: None declared Ethical approval: Not required

\section{REFERENCES}

1. Udainia A, Jain ML. Morphological study of placenta in pregnancy induced hypertension with its clinical relevance. J Anat Soc India. 2001;50:24-7.

2. Benirshke K. The placenta: How to examine it and what you can learn. Contemp Obstet Gynecol. 1981;17:117-9.
3. Bewly S, Cooper D, Campbell S. Doppler investigation of utero-placental blood flow resistance in the second trimester. A screening study for preeclampsia and intra-uterine growth retardation. $\mathrm{Br} \mathbf{J}$ Obst Gynaecol. 1991;98:871-9.

4. Stock MK, Anderson DF, Phernetton TM, McLaughlin MK, Rankin JH. Vascular response of the maternal placental vasculature. J Dev Physiol. 1980;2:239-46.

5. Thomson AM, Billewickz, Hytten FE. Placenta in relation to birth weight. J Obstet Gynecol Br CW. 1969;76:865-72.

6. Majumdar S, Dasgupta $\mathrm{H}$, Bhattacharya $\mathrm{K}$, Bhattacharya A. A study of placenta in normal and hypertensive pregnancies. J Anat Soc India. 2005; 54(2):1-9.

7. Narasimha A, Vasudeva DS. Spectrum of changes in Placenta in toxemia of pregnancy. Indian $\mathbf{J}$ Pathol Microbiol. 2011:54 (1):15-20.

8. Cunningham F, Leveno K, Bloom S, Hauth J, Rouse D, Spong C. Pregnancy Hypertension. Williams Obstetrics: 23rd Ed. United States. McGraw-Hill; 2010; Chapter 34:706-756.

9. Boyd PA, Scott A. Quantitative structural studies on human placenta associated with preeclampsia essential hypertension and intrauterine growth retardation. Br J Obstet Gynaecol. 1985;92:714-21.

10. Udainia A Jain M.L Morphological Study of Placenta in Pregnancy Induced Hypertension with its Clinical Relevance. J Anat Soc India. 2001;50(1):247.

11. Palaskar A, Chaudhary KR, Mayadeo NM. etoplacental weight relationship in normal pregnancy and preeclampsia-eclampsia. Bombay Hospital J. 2001;43(3):361-3.

12. Thanawala U, Khopkar K. Intrauterine growth restriction, Diagnosis and management. In: Desai $\mathrm{P}$, Malhotra, Shah-editors. Principles 127 and Practice of Obstetrics and gynecology. $3^{\text {rd }}$ Ed. Jaypee brothers. New Delhi;2008:204.

13. Mohite SS, Umarji BN, Doshi MA, Karambelkar RR. Normal full term human placentamorphological study. Res J Krishna Institute, Karad. 2009 July;2(2):45-7.

14. Chakravorty AP. Fetal and placental weight changes in normal pregnancy and pre-eclampsia. J Obstet Gynaecol Br Commonwealth. 1967;74:247-53.

Cite this article as: Bandekar PK, Kale PB. Placenta in pregnancy induced hypertension. Int J Reprod Contracept Obstet Gynecol 2018;7:467-9. 